\title{
Time-dependent failure in load-bearing polymers: a potential hazard in structural applications of polylactides
}

\author{
T. H. Smit • T. A. P. Engels • S. H. M. Söntjens • \\ L. E. Govaert
}

Received: 30 June 2009/Accepted: 23 October 2009/Published online: 7 November 2009

(C) The Author(s) 2009. This article is published with open access at Springerlink.com

\begin{abstract}
With their excellent biocompatibility and relatively high mechanical strength, polylactides are attractive candidates for application in load-bearing, resorbable implants. Pre-clinical studies provided a proof of principle for polylactide cages as temporary constructs to facilitate spinal fusion, and several cages already made it to the market. However, also failures have been reported: clinical studies reported considerable amounts of subsidence with lumbar spinal fusion cages, and in an in vivo goat study, polylactide spinal cages failed after only three months of implantation, although mechanical testing had predicted sufficient strength for at least eight months. The failures appear to be related to the long-term performance of polylactides under static loading conditions, a phenomenon which is common to all glassy polymers and finds its origin in stress-activated molecular mobility leading to plastic flow. This paper reviews the mechanical properties and deformation kinetics of amorphous polylactides. Compression tests were performed with various strain rates, and static stress experiments were done to determine time-to failure. Pure PLLA appeared to have a higher yield strength than its co-polymers with D-lactide, but the kinetic behaviour of the polymers was the same: an excellent
\end{abstract}

T. H. Smit $(\bowtie)$

Department of Orthopaedic Surgery, VU University Medical Centre, P.O. Box 7057, 1007MB Amsterdam, The Netherlands e-mail: th.smit@vumc.nl

T. A. P. Engels · S. H. M. Söntjens · L. E. Govaert Polymer Technology, Mechanical Engineering, Eindhoven University of Technology, Eindhoven, The Netherlands

T. H. Smit

Skeletal Tissue Engineering Group, Amsterdam,

The Netherlands short-term strength at higher loading rates, but lifetime under static stress is rather poor. As spinal implants need to maintain mechanical integrity for a period of at least six months, this has serious implications for the clinical application of amorphous polylactides in load bearing situations. It is recommended that standards for mechanical testing of implants made of polymers be revised in order to consider this typical time-dependent behaviour.

\section{Introduction}

The primary function of skeletal tissues is mechanical support. When a skeletal disorder or tissue damage occurs, fixations are required to reposition the structures involved and to create the proper mechanical environment for functional healing. Metal implants are routinely used and quite successful, but they also have drawbacks. First, metals (and non-degradable polymers alike) are permanent materials and as such remain susceptible to long-term complications like wear [1], failure [2], migration [3], and late foreign body reactions $[1,4]$. Therefore, in some countries the removal of metallic implants used for fixation is recommended [5,6]. A second disadvantage of metal implants is that they eclipse the fusion zone on radiological imaging and make it impossible to determine whether healing has been achieved. Finally, metal implants cause stress shielding over the fusion area, resulting in delayed unions [7]. Obviously, these are undesired properties for fixation implants aiming at healing or fusion.

Skeletal fixation devices essentially have a temporary function: once healing is achieved, removal is desired both from the clinical and biomechanical point of view. This has motivated the development of degradable polymer 
implants $[8,9]$, which have evident advantages over metal devices: their stiffness is comparable to that of bone; they do not interfere with radiography, computer tomography, or magnetic resonance imaging [10]; and they degrade over time and thus eliminate the necessity of retrieval surgeries. In addition, the healing process may be stimulated by the successive loss of their mechanical properties, thereby gradually increasing the loads on the healing tissues [7]. Polylactides like poly(L-lactic acid) (PLLA) are attractive materials for this purpose because they are relatively strong and their biocompatibility is known to be excellent. A proof of concept of spinal fusion with degradable cages was provided in a long-term goat study [7, 11, 12], showing that PLLA cages resulted in faster fusion as compared to stiff titanium cages and full degradation occurred within four years without adverse foreign body reactions [13] (Fig. 1a). The results of this animal study have been translated into a degradable cage for cervical spinal fusion (www.SolisRS.com; Fig. 1b), for which a clinical proof of concept was obtained as well (Fig. 1c).

PLLA is a semi-crystalline polymer, which implies that crystalline particles remain in the host tissue after degradation of the amorphous parts of the implant. These particles degrade more slowly and as such may act as splinters and invoke a tissue reaction by the host. Although no such effects were observed in the aforementioned goat studies [13], long-term complications like osteolytic reactions have been reported with other semi-crystalline polymers in literature [14-18]. For that reason, amorphous polymers are generally favoured for the clinical application of degradable implants. PLLA can be made amorphous by adding $15 \%$ or more of the D-enantiomer [19]. When L- and D-isomers are co-polymerized in equal proportions, a racemic (50/50) polylactide is formed. Its molecular chains cannot easily pack together to crystallize, because the side groups are located on both sides of the polymer backbone.
Consequently, racemic polylactide (PDLLA) is entirely amorphous. Non-racemic copolymers are usually mixed from L-lactide and a racemic mixture of $\mathrm{D}$ - and L-lactide: poly(L-D,L-lactic acid). 70:30 PLDLLA, for example, indicates the molar ratio of L-lactide $(70 \%)$ and the racemic DL-lactide mixture (30\%). This polymer thus contains $85 \%$ L- and $15 \%$ D-isomers of lactic acid. Less common mixtures in the orthopaedic literature are 80:20, 85:15, and 96:4.

Under the name Hydrosorb ${ }^{\text {TM }}$, 70/30 PLDLLA was one of the earliest and the most commonly used polylactides clinically applied in degradable cages [20-25]. The material combines mechanical strength $[26,27]$ with excellent biocompatibility, and excellent clinical results were obtained initially $[20,21,25]$. Later, however, important clinical observations were made by Herceg and colleagues [22], who found rapid and massive subsidence of Hydrosorb $^{\text {TM }}$ (70/30 PLDLLA) cages in patients undergoing lumbar spinal fusion. This finding was recently confirmed by Jiya and colleagues [23] and the same was observed in a large animal (goat) study [28], which allowed a more detailed analysis of this phenomenon: implants which presumably had sufficient strength for bearing spinal loads for at least eight months [26], were broken and deformed after only three months (Fig. 2) [28]. It appeared in additional studies, that the mechanical strength of 70/30 PLDLLA was lower for lower loading rates, higher temperature, and higher humidity [29]. In other words: 70/30 PLDLLA appears to show strong time- and load-dependent behaviour which is actually typical for glassy polymers [30].

In the following, we further investigate this phenomenon and study the long-term behaviour of three relevant polylactides: 70/30 poly(L,DL-lactic acid) (PLDLLA) and the components it consists of: stereoregular poly(L-lactic acid) (PLLA), and racemic (50/50) poly(D,L-lactic acid)
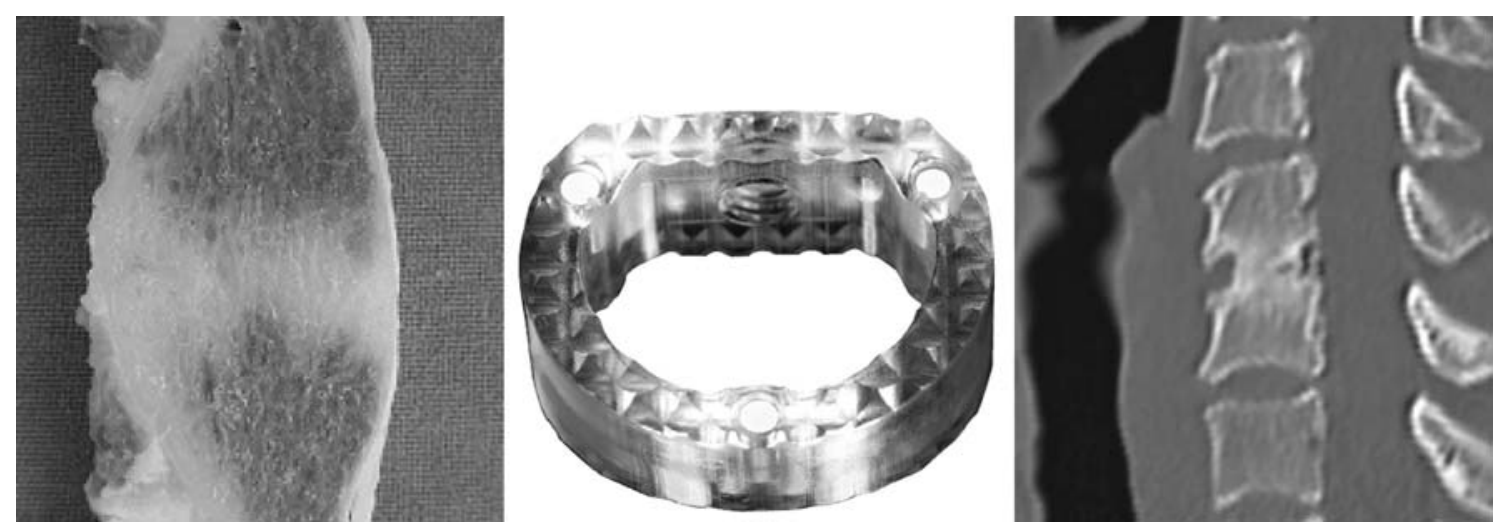

Fig. 1 Proof of concept of spinal fusion with degradable cages made of PLLA. a lumbar spinal fusion in a goat model after four years of implantation. No remnants of the cage are left. b The degradable Solis
RS cage for cervical spinal fusion. c The first clinical proof of concept: cervical spinal fusion after only four months of follow-up 


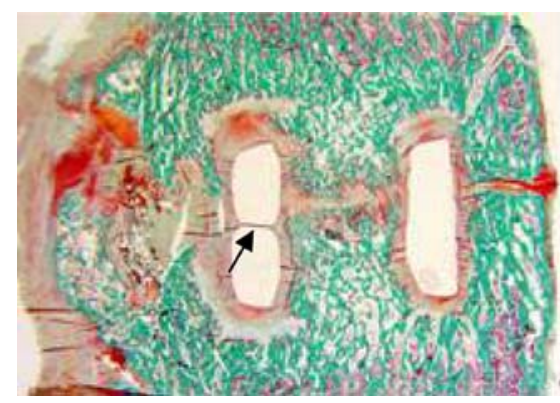

Fig. 2 70/30 PLDLLA cage after three and six months follow-up in a goat spine. a Histology shows micro-cracks already after three months of implantation (arrow). b Micro-MRI confirms that brittle micro-cracks are formed (arrow), originating from the notches on the

(PDLLA). The homopolymer PLLA is generally considered semi-crystalline, but initial crystallinity can be minimised by the manufacturing process (fast cooling after moulding). The mechanical behaviour of these three polylactides will be quantified in a series of short- and long-term loading experiments. It will be shown that the polylactides are brittle and strong at high loading rates, but weak and ductile under static loading conditions. This finding has important implications for the way load-bearing polymer implants should be tested to obtain FDA- or CEclearance for clinical application.

\section{Materials}

As discussed, the materials to be studied are an equivalent to Hydrosorb ${ }^{\text {TM }} 70 / 30$ blend of poly(L-lactic acid) with a stereo-irregular poly(D,L-lactic acid) copolymer (PLDLLA); a stereo-regular poly(L-lactic acid) homopolymer (PLLA); and a racemic poly(D,L-lactic acid) copolymer (PDLLA). All materials were kindly provided by PURAC Biochem (Gorinchem, The Netherlands). For the shortterm mechanical loading experiments, none of the polymers was sterilized. The initial properties of the materials as determined by the supplier are given in Table 1 .

For compression testing, granules were compression moulded into $10 \mathrm{~mm}$ thick rectangular plaques at $200^{\circ} \mathrm{C}$ and successively cooled rapidly to room temperature by water cooled plates. This prevents the formation of crystals

Table 1 Properties of the polymers as provided by the supplier

\begin{tabular}{llll}
\hline Polymer & $\mathrm{IV}(\mathrm{dl} / \mathrm{g})$ & $\mathrm{M}_{\mathrm{w}}(\mathrm{g} / \mathrm{mol})$ & $\mathrm{T}_{\mathrm{g}}\left({ }^{\circ} \mathrm{C}\right)$ \\
\hline 70/30 PLDLLA & 7.37 & $1,901,000$ & 58 \\
PLLA & 8.28 & $2,155,000$ & 61 \\
PDLLA & 4.20 & $1,139,000$ & 57 \\
\hline
\end{tabular}

From left to tight: Inherent viscosity (IV) determined in $0.1 \mathrm{~g} / \mathrm{dl}$ chloroform; weight-averaged molecular weight $\left(\mathrm{M}_{\mathrm{w}}\right)$; and glass transition temperature $\left(\mathrm{T}_{\mathrm{g}}\right)$ as measured by DSC rims of the cage (inset). Also some plastic deformation of the cage is visible. c After six months, severe deformation of the cage is typically seen, along with failed fusion in more than $50 \%$ of the cases [28]

particularly in PLLA. From the compression moulded plaques, cylinders with a diameter and height of $6 \mathrm{~mm}$ were machined. During all machining operations the materials were cooled by air.

To bring the findings into clinical perspective, longterm, real-time degradation tests were performed with experimental spinal cages made of 70/30 PLDLLA, similar to Hydrosorb ${ }^{\mathrm{TM}}$ which had shown mechanical failure in the clinic. The cages used in this study were intended for usage in the goat model and had an open-box geometry, sized $18 \times 10 \times 10 \mathrm{~mm}$ and a wall thickness of $1.5 \mathrm{~mm}$. As in the clinically used Hydrosorb ${ }^{\mathrm{TM}}$, the cages were sterilized by e-beam, except for one series of cages which was sterilized by Ethylene Oxide (EtO).

\section{Methods}

Since spinal cages are mainly loaded under compression and amorphous polylactides behave brittle in extension [19], compressive rather than tensile testing was performed. Tests were done on a servo-hydraulic MTS Elastomer Testing System 831 using a temperature chamber at 0,22 and $37^{\circ} \mathrm{C}$. Constant applied strain rate experiments were done with constant true strain rate control at rates of $10^{-2}, 10^{-3}$ and $10^{-4} \mathrm{~s}^{-1}$. Constant applied stress experiments were performed under true stress control at various stress levels. All loads were applied within $5 \mathrm{~s}$. Friction between samples and compression platens was reduced by applying a thin film of skived PTFE tape (3M 5480) on the sample ends and spraying PTFE lubricant on the compression platens. True stresses and true strains were calculated with the assumption of incompressibility, which is common practice as the Poisson's ratio of glassy polymers is large $(>0.45)$ and in the post-yield region the material shows rubber-like behaviour.

For the long-term experiments under low mechanical loading conditions, the spinal cages were placed in $0.9 \%$ $\mathrm{NaCl}$ at $37^{\circ} \mathrm{C}$. E-beam sterilized cages were loaded under 
static compression $(500 \mathrm{~N})$ or a dynamic loading regime $(300 \pm 200 \mathrm{~N} ; 300 \pm 33 \mathrm{~N}$; or $100 \pm 33 \mathrm{~N})$. To assess a potential role of sterilization, one group of cages loaded at $300 \pm 200 \mathrm{~N}$ were sterilized by EtO. The duration of loading was 3, 6, 13 or 26 weeks. After these periods, the decrease of cage height was determined as a measure of plastic deformation.

\section{Results and discussion}

The time-dependent failure of glassy polymers is illustrated by the behaviour of PLLA in compression under a variety of strain rates and stresses (Figs. 3 and 4). Figure 3 (left) shows the intrinsic behaviour of PLLA as measured under compression at a constant true strain rate, resulting in homogeneous deformation over large strains. Initially the material behaves linear-elastic, eventually reaching a maximum: the yield stress (here at $4 \%$ strain and a stress of app. $94 \mathrm{MPa}$ ). Subsequently, two characteristic phenomena are observed [30]: (1) Strain softening, the initial decrease of true stress with strain, which implies that less energy is required for further deformation of the specimen, so that failure continues. (2) Strain hardening, the subsequent upswing of the true stress-strain curve, which implies that further deformation requires more energy, thereby inhibiting further failure. The interplay between strain softening and strain hardening for a large extend determines the toughness of a material: materials with strong softening and weak hardening behave brittle, and materials with weak softening and strong hardening tough [31]. Polylactides thus fail brittle, at least under higher loading rates, and this was also observed in the in vivo goat study [28] (Fig. 2b). For the designer of polylactide implants, this implies that stress concentrations, such as holes or sharp teeth on the rims of cages, should be avoided.

Time-dependent failure of glassy polymers also becomes evident when a constant stress is applied on a similar sample (Fig. 3, right). The stress applied (50 MPa) is only $53 \%$ of the yield stress (94 MPa) as measured in Fig. 3 (left). Initially the sample reacts with an elastic response of app. $2 \%$ strain, after which the deformation increases gradually to app. 5\% strain after $1800 \mathrm{~s}$ (half an hour). Then the strain rate increases dramatically, resulting in catastrophic failure after only $2100 \mathrm{~s}(35 \mathrm{~min})$. Ductile failure under a constant stress is also called delayed yielding, because the moment of localization can take considerable time, depending on the applied load. Plastic deformation was also observed in the cages used in the goat model (Fig. 2). The remarkable fact thus occurs that these spinal cages failed in both modes, brittle and ductile: the former under short-term, high loading rates, the latter under long-term, low-amplitude loading.
Fig. 3 Left: Compressive true stress versus true strain measured at a constant true strain rate. Right: Compressive true strain versus loading time measured under a constant stress

Fig. 4 Left: True strain versus loading time for increasing stresses. Right: Stress dependence of the time-tofailure $(-\alpha)$. Dots are single measurements
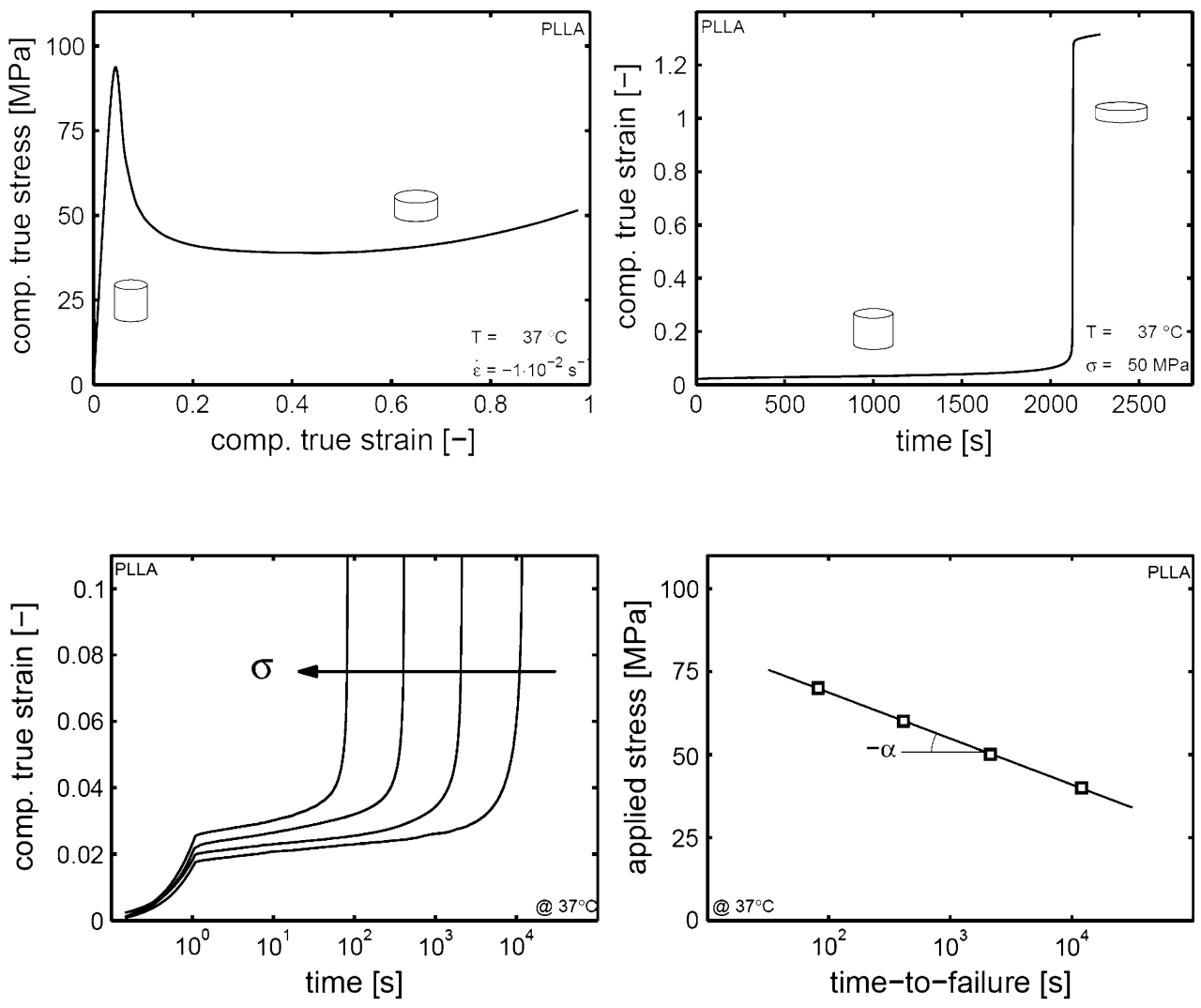
The time-dependent response of the material strongly depends on the loading conditions applied. Figure 4 shows the true strain versus loading time for four static loading levels (left). It can be seen that by increasing the loads, time-to-failure can be significantly decreased (note the logarithmic time scale). For example, a stress of $70 \mathrm{MPa}$ results in a catastrophic failure in less than $100 \mathrm{~s}$, a load of $40 \mathrm{MPa}$ leads to failure in about $3 \mathrm{~h}$. It can be shown [30] that a semi-logarithmic relation exists between the applied stresses and the corresponding times-to-failure. For PLLA it appears that an increase in applied stress of about $14 \mathrm{MPa}(\alpha)$ leads to a decrease in lifespan by an order of ten. From this the conclusion can be drawn that it is not the question whether the material will fail under a static load, but rather when it will fail under the specified conditions.

To illustrate this further, the yield point is investigated a bit closer. With increasing strain rate, the yield point is also observed to increase (Fig. 5, left). Taking the yield stresses and plotting them versus the applied strain rate results again in a semi-logarithmic relation (Fig. 5, right), with a slope $\alpha$ equal to that found in the time-to-failure plot (Fig. 4, right). Higher temperature and humidity decrease the yield stress of PLLA, but its kinetic behaviour (in particular: slope $\alpha$ in the time-to-failure plot) remains the same [29, 32].

The comparison between PLLA, 70/30 PLDLLA and (racemic) PDLLA is given in Fig. 6. From the plots it appears that PLLA is stronger than PDLLA and PLDLLA, e.g. at a strain rate of $0.001 / \mathrm{s}$ the yield strengths are 81,78 and $71 \mathrm{MPa}$, respectively. The dependence of strain rate (slope $\alpha$ of the dashed line), however, is the same for all three materials. This is also found considering lifetime under constant stress: PLLA is slightly stronger than PDLLA and PLDLLA, but due to the strong rate dependence (14 MPa/decade) the difference in life time between PLLA and 70/30 PLDLLA is approximately a factor 2. This may explain why PLLA cages did not fail in the goat model [7], where PLDLLA cages did [11, 28].

In order to place previous findings into clinical perspective, we also compressed e-beam sterilised 70/30 PLDLLA cages under real-time degradation conditions (Fig. 7). Cages with an original height of $10 \mathrm{~mm}$ had a yield strength of $7.1 \mathrm{kN}$ at a strain rate of $1.3 \mathrm{~mm} / \mathrm{min}$ $(0.2 \mathrm{~mm} / \mathrm{s})$ [33]. When placed under a static load of only
Fig. 5 Left: True stress versus strain for increasing strain rates for PLLA at $37^{\circ} \mathrm{C}$. Right: Rate dependence of the yield stress $(\alpha)$. Dots are single measurements
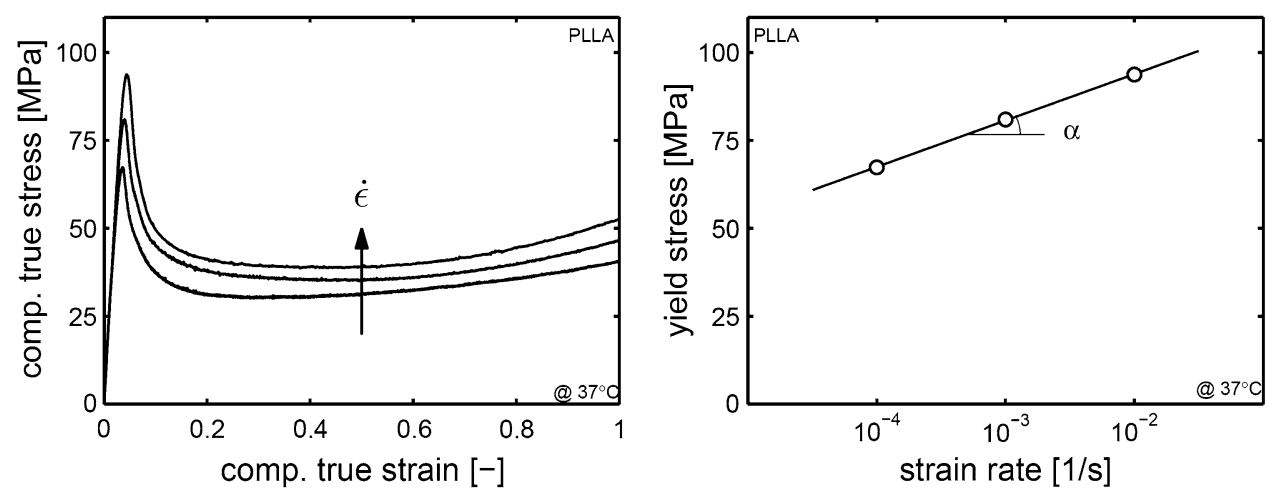

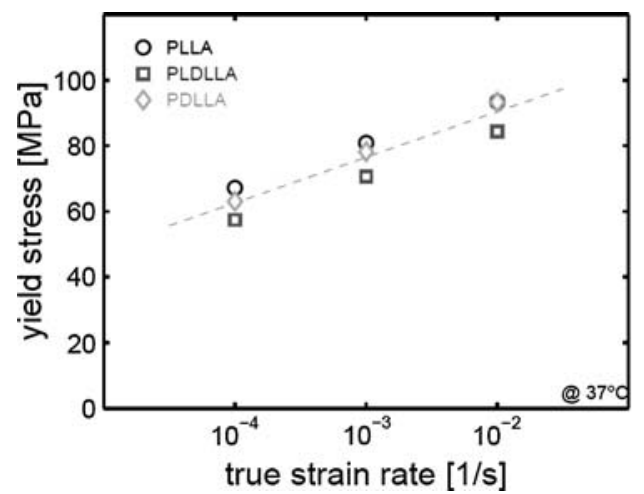

Fig. 6 Left: Yield stress vs. strain rate in uniaxial compression for PLLA, PLDLLA and PDLLA. Measurements are duplicated twice $(n=3)$, standard deviations are smaller than the dots. Right: Time-tofailure vs. applied stress in uniaxial compression for PLLA, PLDLLA

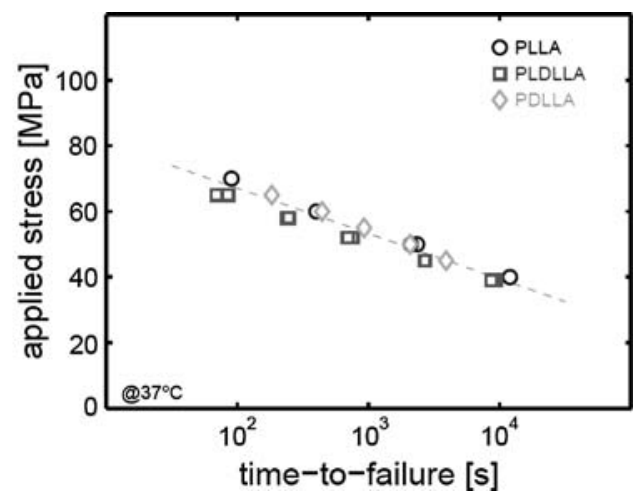

and PDLLA. Dots shown here are single measurements. The dashed lines in both plots are computer estimations for the behaviour of polylactides, in which the data of the three polymers are pooled. Details of the computer model are described elsewhere [32, 35] 
Fig. 7 Plastic deformation of e-beam sterilised 70/30 PLDLLA cages (top right) with an original height of $10 \mathrm{~mm}$ under various low-loading regimes. After three months of compressive loading at $500 \mathrm{~N}$, the cage was severely deformed (lower right). When sterilized by EtO, the cages showed much less deformation (open circles)
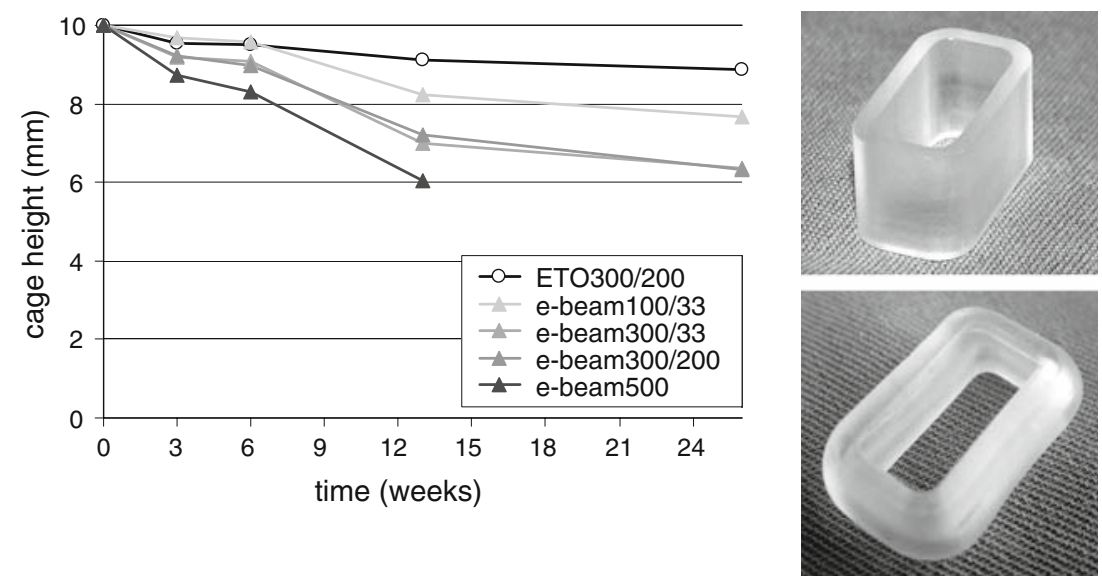

$500 \mathrm{~N}$, plastic deformation was more than $1 \mathrm{~mm}$ after only three weeks of loading, and at 3 months, the cage had failed entirely (Fig. 7, right). It should be emphasised, that the instantaneous strength (i.e. the yield strength at a loading rate of $1.3 \mathrm{~mm} / \mathrm{min}$ ) after 6 months of real-time degradation at $37^{\circ} \mathrm{C}$ without loading was still $5.8 \mathrm{kN}$ [33], an order of magnitude higher than the load applied in this experiment. Thus, plastic deformation of the cage is due to viscous flow of PLDLLA, not to degradation.

Decreasing the static load $(300 \mathrm{~N}, 100 \mathrm{~N})$ resulted in less cage deformation, but dynamic loading did not make a difference: adding a dynamic load with an amplitude of $200 \mathrm{~N}$ did not result in more deformation than adding a dynamic load with an amplitude of $33 \mathrm{~N}$. Note that even under a marginal load of $100 \mathrm{~N}$, plastic deformation was more than $2 \mathrm{~mm}$ after six months. Six months is a very long period for dynamic testing in the lab, but in fact is the minimal life-time for spinal cages to maintain their mechanical properties.

Sterilisation proved to have a major impact on the deformation of the cages under long-term, low-amplitude loading conditions (Fig. 7). While e-beam sterilized cages showed a height loss after six months of almost $4 \mathrm{~mm}$, the EtO-sterilised cages showed a height loss of only $1.1 \mathrm{~mm}$. This is surprising, considering the fact that the instantaneous strength of non-loaded EtO- and e-beam sterilized cages (i.e. the strength measured at $1.3 \mathrm{~mm} /$ min) had been reported to be more or less equal for cages sterilized either way [33]. However, e-beam was shown to reduce inherent viscosity of the polymer to about onethird of its original value, a decrease which would take a year for hydrolytic degradation [33]. Thus, it can be stated that e-beam sterilization shifts forward the chemical degradation of 70/30 PLDLLA by about one year. Presumably, shorter polymers are more mobile under prolonged loading conditions, which may explain the strong deformation of the e-beam- as compared to the EtO-sterilized samples. As sterilization is mandatory for all implants including degradable polymers, this phenomenon requires further investigation.

The rate dependence of the polylactides examined in this study is about $14 \mathrm{MPa}$ /decade (slope $\alpha$ in Figs. 4, 5, and 6). For comparison, polycarbonate (PC) has a value of 3-4 MPa/decade [30], and poly(etheretherketone) (PEEK) about $4 \mathrm{MPa} /$ decade [34]. Thus, it can be concluded that the rate dependence of polylactides is rather high as compared to other polymeric biomaterials. For example, the strength of the PLLA as measured under high strain rates is higher than that of PC (Fig. 8, left), but under low loading conditions PC outperforms PLLA already after 6 h (Fig. 8,
Fig. 8 Uniaxial compression results for PLLA and PC. Left: Yield stress versus strain rate $(n=3)$. Right: Time-to-failure versus applied stress (single measurements)
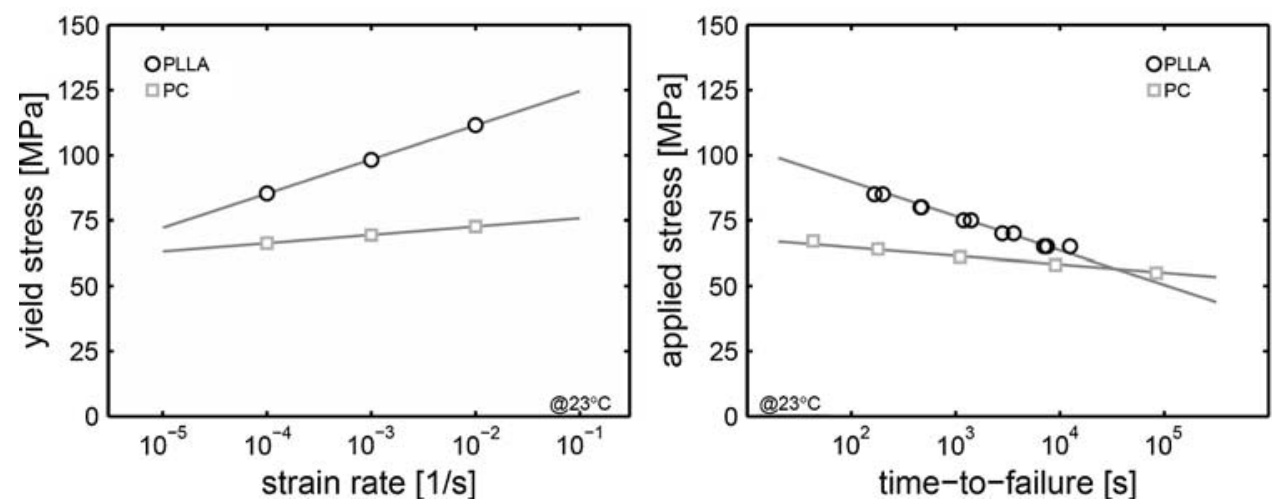
right). This further illustrates that knowledge of the instantaneous strength of a polymeric material is insufficient to predict its applicability under load over long times.

To avoid long-term complications with permanent implants, the concept of degradable materials have drawn considerable attention over the last decades $[8,9]$. Polylactides are interesting polymers because their biocompatibility is excellent and they show relatively high mechanical strength. However, clinical [22, 23] and preclinical data $[28,29]$ showed that the long-term behaviour of polylactides under prolonged mechanical loading is rather poor: severe plastic deformation is observed in PLDLLA implants after relatively short periods of time (half a year). Further analyses revealed that this behaviour is due to the intrinsic properties of amorphous polylactides, rather than degradation of the polymer [29, 30, 32]. PLLA performs somewhat better than 70/30 PLDLLA, but the kinetic behaviour is essentially the same. Sterilisation does not seem to affect the instantaneous strength of the polymer [29], but the long-term behaviour under continuous loading can be affected drastically (Fig. 7).

It is important to note that cages used in the clinic, like the Hydrosorb Telamon and the SolisRS, have met requirements set by standardized testing protocols. ASTMF2077 describes static loading tests at relatively high loading rate, ASTM-F1798 describes fatigue testing. However, such tests do not address the long-term behaviour of these materials under prolonged loading. For example, fatigue testing of 1.3 million cycles at $1 \mathrm{~Hz}$. takes about 15 days. This is quite long for a testing protocol, but for a load bearing implant like a spinal cage a minimum loading time of six to twelve months is required. So, implants that do meet the ASTM standards still may fail in practice, as was indeed observed e.g. with the Hydrosorb 70/30 PLDLLA cages [22, 23]. It thus seems appropriate to reconsider such protocols for load-bearing constructs when these are made of polymers like amorphous PLA's. Predictive models as described by Govaert and colleagues $[32,35,36]$ could be helpful, because they allow estimating the long-term performance of a degradable construct in early stages of design.

\section{Conclusions}

To gain more insight in the premature failure of spinal implants made of amorphous polylactides, the intrinsic deformation kinetics of these materials were studied in more detail. The rate dependence of polylactides was found to be high with respect to other materials frequently used in medical applications. The plastic flow observed in glassy polymers implies that a construct will always fail under static load, the only question being when. This calls for a new approach to the design of load-bearing polymer implants. Furthermore, new ASTM standards for mechanical testing are required to secure safe application of glassy polymers under long-term static loading conditions.

Acknowledgement The work of SHMS has been supported by the Dutch Polymer Institute (DPI grant \# 614).

Open Access This article is distributed under the terms of the Creative Commons Attribution Noncommercial License which permits any noncommercial use, distribution, and reproduction in any medium, provided the original author(s) and source are credited.

\section{References}

1. Togawa D, Bauer TW, Lieberman IH, et al. Lumbar intervertebral body fusion cages: histological evaluation of clinically failed cages retrieved from humans. J Bone Joint Surg Am. 2004;86-A:70-9.

2. Button G, Gupta M, Barrett C, et al. Three- to six-year follow-up of stand-alone BAK cages implanted by a single surgeon. Spine J. 2005;5:155-60.

3. Taneichi H, Suda K, Kajino T, et al. Unilateral transforaminal lumbar interbody fusion and bilateral anterior-column fixation with two Brantigan I/F cages per level: clinical outcomes during a minimum 2-year follow-up period. J Neurosurg Spine. 2006;4:198-205.

4. Ohlin A, Karlsson M, Duppe H, et al. Complications after transpedicular stabilization of the spine. A survivorship analysis of 163 cases. Spine. 1994;19:2774-9.

5. Brantigan JW, Steffee AD, Lewis ML, et al. Lumbar interbody fusion using the Brantigan $\mathrm{I} / \mathrm{F}$ cage for posterior lumbar interbody fusion and the variable pedicle screw placement system: two-year results from a Food and Drug Administration investigational device exemption clinical trial. Spine. 2000;25:1437-46.

6. Mueller M, Allgoewer M, Schneider R, et al. Manual of internal fixation. Techniques recommended by the AO Group. 2nd ed. New York: Springer; 1979.

7. van Dijk M, Smit TH, Sugihara S, et al. The effect of cage stiffness on the rate of lumbar interbody fusion: an in vivo model using poly(L-lactic acid) and titanium cages. Spine. 2002;27:682-8.

8. Middleton JC, Tipton AJ. Synthetic biodegradable polymers as orthopedic devices. Biomaterials. 2000;21:2335-46.

9. Wuisman PI, Smit TH. Bioresorbable polymers: heading for a new generation of spinal cages. Eur Spine J. 2006;15:133-48.

10. Cordewener FW, Bos RR, Rozema FR, et al. Poly(L-lactide) implants for repair of human orbital floor defects: clinical and magnetic resonance imaging evaluation of long-term results. J Oral Maxillofac Surg. 1996;54:9-13.

11. Smit TH, Krijnen MR, van Dijk M, et al. Application of polylactides in spinal cages: studies in a goat model. J Mater Sci Mater Med. 2006;17:1237-44.

12. van Dijk M, Smit TH, Burger EH, et al. Bioabsorbable poly-Llactic acid cages for lumbar interbody fusion: three-year followup radiographic, histologic, and histomorphometric analysis in goats. Spine. 2002;27:2706-14.

13. van Dijk M, van Diest PJ, Smit TH, et al. Four-year follow-up of poly-L-lactic acid cages for lumbar interbody fusion in goats. J Long Term Eff Med Implants. 2005;15:125-38.

14. Bergsma EJ, Rozema FR, Bos RR, et al. Foreign body reactions to resorbable poly(L-lactide) bone plates and screws used for the fixation of unstable zygomatic fractures. J Oral Maxillofac Surg. 1993;51:666-70. 
15. Bergsma JE, de Bruijn WC, Rozema FR, et al. Late degradation tissue response to poly(L-lactide) bone plates and screws. Biomaterials. 1995;16:25-31.

16. Bostman OM. Osteoarthritis of the ankle after foreign-body reaction to absorbable pins and screws: a three- to nine-year follow-up study. J Bone Joint Surg Br. 1998;80:333-8.

17. Bostman OM, Pihlajamaki HK. Late foreign-body reaction to an intraosseous bioabsorbable polylactic acid screw. A case report. J Bone Joint Surg Am. 1998;80:1791-4.

18. Hoffmann R, Weller A, Helling HJ, et al. Local foreign body reactions to biodegradable implants. A classification. Unfallchirurg. 1997;100:658-66.

19. Grijpma DW, Pennings AJ. (Co)polymers of L-lactice, 2 Mechanical properties. Macromol Chem Phys. 1994;195:1649-63.

20. Austin RC, Branch CL Jr, Alexander JT. Novel bioabsorbable interbody fusion spacer-assisted fusion for correction of spinal deformity. Neurosurg Focus. 2003;14:e11.

21. Couture DE, Branch CL Jr. Posterior lumbar interbody fusion with bioabsorbable spacers and local autograft in a series of 27 patients. Neurosurg Focus. 2004;16:E8.

22. Herceg MB, Slosar PJ, Josey R. Rapid subsidence in lumbar interbody spinal fusion with resorbable implants. In: 19th Ann. meeting North American Spine Society; 2004. Ref Type: Conference Proceeding.

23. Jiya T, Smit T, Deddens J, et al. Posterior lumbar interbody fusion using nonresorbable poly-ether-ether-ketone versus resorbable poly-L-lactide-co-D,L-lactide fusion devices: a prospective, randomized study to assess fusion and clinical outcome. Spine (Phila Pa 1976). 2009;34:233-7.

24. Lanman TH, Hopkins TJ. Lumbar interbody fusion after treatment with recombinant human bone morphogenetic protein-2 added to poly(L-lactide- $c o$-D,L-lactide) bioresorbable implants. Neurosurg Focus. 2004;16:E9.

25. Vaccaro AR, Singh K, Haid R, et al. The use of bioabsorbable implants in the spine. Spine J. 2003;3:227-37.

26. Cornwall GB, Thomas KA, McManus AJ. Compressive strength retention of 70:30 poly(L-lactide-co-D,L-lactide) following real time ageing. In: Society for biomaterials 29th annual meeting transactions. Minneapolis: Society for Biomaterials; 2003. p. 393. Ref Type: Abstract.

27. Moser RC, McManus AJ, Riley SL, et al. Strength retention of 70:30 poly(L-lactide-co-D,L-lactide) following real-time aging. J Biomed Mater Res B Appl Biomater. 2005;75:56-63.

28. Krijnen MR, Mullender MG, Smit TH, et al. Radiographic, histologic, and chemical evaluation of bioresorbable 70/30 poly-Llactide-co-D,L-lactide interbody fusion cages in a goat model. Spine. 2006;31:1559-67.

29. Smit TH, Engels TA, Wuisman PI, et al. Time-dependent mechanical strength of 70/30 Poly(L, DL-lactide): shedding light on the premature failure of degradable spinal cages. Spine. 2008;33:14-8.

30. Klompen ETJ, Engels T, Govaert LE, et al. Modeling of the postyield response of glassy polymers: influence of thermomechanical history. Macromolecules. 2005;38:6997-7008.

31. Meijer HEH, Govaert LE. Multi-scale analysis of mechanical properties of amorphous polymer systems. Macromol Chem Phys. 2003;204:274-88.

32. Engels TA, Sontjens SH, Smit TH, et al. Time-dependent failure of amorphous polylactides in static loading conditions. J Mater Sci Mater Med. 2009.

33. Smit TH, Thomas KA, Hoogendoorn RJ, et al. Sterilization and strength of 70/30 polylactide cages: e-beam vs. ethylene oxide. Spine. 2007;32.

34. Hamdan S, Swallowe GM. The strain-rate and temperature dependence of the mechanical properties of polyetherketone and polyetheretherketone. J Mater Sci. 1996;31:1415-23.

35. Klompen ETJ, Engels T, van Breemen L, et al. Quantitative prediction of long-term failure of polycarbonate. Macromolecules. 2005;38:7008-17.

36. Meyer H, Govaert LE. Mechanical performance of polymer systems: the relation between structure and properties. Prog Polym Sci. 2005;30:915-38. 